\title{
Short-Term Outcome in Patients with Acute Ischemic Stroke on the Basis of Admission Plasma D-Dimer Level
}

\author{
DHAR K ${ }^{1}$, HABIB M$^{2}$, GHOSE SK ${ }^{3}$, AHMED KGU $^{4}, \mathrm{CHOWDHURY} \mathrm{AH}^{5}$, SHAHA K $^{6}$, SINA H$^{7}$
}

\begin{abstract}
:
Background: Elevated levels of plasma D-dimer increase the risk of ischemic stroke, stroke severity, and the progression of stroke status, but the association between plasma D-dimer level and functional outcome is unclear. Methods: This observational cohort type of study was done in the Department of Neurology Dhaka Medical College Hospital, Dhaka during August, 2017 to July, 2019. Total 100 patients having acute ischemic stroke were included in this study. Age > 18 year of both male \& female patients with first-ever acute ischemic stroke confirmed by CT scan/MRI who gave informed written consent including consent to give blood sample for plasma D-dimer level measurement were enrolled in this study. RESULTS: Mean D-dimer level was $0.49 \pm 0.00$ found in MRS $0,0.57 \pm 0.19$ in MRS $1,0.49 \pm 0.00$ in MRS 2, $0.70 \pm 0.33$ in

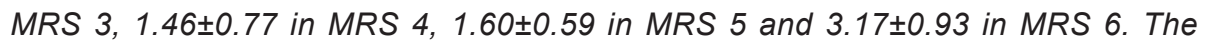
above findings indicate that MRS score increased with mean D-dimer significantly $(p<0.05)$. Receiver-operator characteristic (ROC) was constructed by using D-dimer level, which gave a cut off value 1.7 , with $90.9 \%$ sensitivity and $89.4 \%$ specificity for prediction of prognosis. Conclusion: Elevated plasma D-dimer level on admission was significantly associated with short-term poor outcome in patients with acute ischemic stroke.
\end{abstract}

Keywords: Ischemic stroke, D-dimer, MRS, Outcome etc

\section{Introduction:}

Stroke is the second highest cause of death worldwide ${ }^{1}$. Approximately 15 million new acute stroke events occur every year and approximately 55 million people have had a stroke at sometime in the past. Two-thirds of these individuals live in the low $\&$ middle income countries ${ }^{2}$. According to the latest WHO data, death due to stroke in Bangladesh reached about $8.5 \%$ of total deaths ${ }^{3}$. Ischemic stroke is one of the major cause of death and places a tremendous burden on health resources. Timely intervention can dramatically improve outcome \& reduce disability. D-dimer, the final product of plasmin-mediated degradation of fibrin-rich thrombi has emerged as a simple blood test that can be used in diagnostic algorithm for the exclusion of venous thrombo-embolism ${ }^{4}$. D-dimer level has certain advantages over other measures of thrombin generation because it's resistant to ex-vivo activation, relatively stable \& has a long half-life ${ }^{5}$. It has been suggested that moderatetly elevated circulating D-dimer values reflect minor increases in blood coagulation, thrombin formation and turnover of cross-linked intravascular fibrin ; and these increases may be associated with coronary heart disease ${ }^{6}$. Patients with higher d-dimer levels are at higher risk of cardiovascular events even if they're receiving oral anti-coagulants ${ }^{7}$. Elevated D-dimer concentrations are of prognostic significance in

1. Dr. Kinghshuk Dhar, Resident (Neurology), Dhaka Medical College (DMCH), Dhaka.

2. Dr. Mansur Habib, Professor (Retd.), Department of Neurology, DMCH, Dhaka.

3. Dr. Swapan Kumar Ghose, Associate Professor (Retd.) Dept. of Neurology, DMCH, Dhaka.

4. Dr. Kazi Giasuddin Ahmed, Associate Professor, Dept. of Neurology, DMCH, Dhaka.

5. Dr. Ahmed Hossain Chowdhury, Associate Professor, Dept. of Neurology, DMCH, Dhaka.

6. Dr. Konol Shaha, Associate Professor, Dept. of Neurology, DMCH, Dhaka.

7. Dr. Hashmi Sina, Assistant Professor, Dept. of Neurology, DMCH, Dhaka. 
long-term neurologic outcomes in childhood-onset arterial ischemic stroke ${ }^{8}$. Elevated D-dimer level has also been shown to relate to early clinical progression $^{9}$, stroke subtypes ${ }^{10}$, infarction volume ${ }^{11}$ and unfovourable outcome ${ }^{12}$ in ischemic stroke patients .On the contrary, Haapaniemi and Tatlisumak, supposed that D-dimer level per se is not an independent predictor for poor outcome but reflects stroke etiology ${ }^{13}$. Thus, the purpose of this study is to find out the association between plasma D-dimer level at admission and short-term functional outcome in Bangladeshi patients with acute ischemic stroke.

\section{Methods:}

The study was carried out in the department of Neurology of Dhaka Medical college Hospital. Patients were collected from the departments of Neurology and Medicine. Following admission, patients with acute ischemic stroke was sorted out according to inclusion \& exclusion criteria. History regarding demographic profile (age, sex); risk factors (hypertension, diabetes mellitus, smoking habit \& alcohol abuse) and clinical presentation was noted on the questionnaire. At admission the neurological deficit was quantified using the National Institutes of Health stroke scale (NIHSS).Under proper aseptic precautions blood sample was collected \& sent for estimation of plasma D-dimer level to the laboratory of the Department of Hematology, Dhaka Medical College Hospital. The value of plasma D-dimer was considered for further analysis. Functional outcome of the patients was assessed with Modified Rankin Scale (MRS) by the principal investigator at day 90. Personal contact number of each patient was collected during interview. Subjects with incomplete data was excluded before final analysis.

\section{Results:}

Table VIII shows the distribution of the study patients by age. It was observed that almost one third $(28.7 \%)$ patients belonged to age $50-59$ years who were in alive group, but more than half $(54.5 \%)$ of patients belonged to age 60-69 years were dead.
The mean age was $59.97 \pm 12.41$ years in alive and $64.27 \pm 6.68$ years in death. The difference of age was statistically not significant $(p>0.05)$ between two groups.

Table X shows the distribution of the study patients by risk factor. It was observed that majority $(83.3 \%)$ patients had hypertension in alive and $15(68.2 \%)$ death, followed by $33(50.0 \%)$ DM in alive and $13(59.1 \%)$ in death, $21(31.8 \%)$ Hyperlipidemia in alive and $11(50.0 \%)$ in death, $20(30.3 \%)$ smoker in alive and $11(50.0 \%)$ in death and $3(4.5 \%)$ others in alive. The risk factors was statistically not significant $(p>0.05)$ between two groups.

According to association between MRS score with D-dimer level it was observed that the mean Ddimer level was $0.49 \pm 0.00$ found in MRS 0 , $0.57 \pm 0.19$ in MRS $1,0.49 \pm 0.00$ in MRS 2, $0.70 \pm 0.33$ in MRS $3,1.46 \pm 0.77$ in MRS 4, $1.60 \pm 0.59$ in MRS 5 and $3.17 \pm 0.93$ in MRS 6. The above findings indicate that MRS score increased with the mean D-dimer level.

All patients were divided into two groups according to plasma D-dimer level. Patients having D-dimer level $<1.5 \mu \mathrm{g} / \mathrm{ml}$ was considered as group I and Ddimer level $\geq 1.5 \mathrm{ig} / \mathrm{ml}$ was considered as group II. Regarding the association between MRS with Ddimer level the mean MRS was $2.54 \pm 1.24$ and $5.38 \pm 0.92 \mathrm{in} \mathrm{D-dimer} \mathrm{level}<1.5 \mathrm{ig} / \mathrm{ml}$ (Group I) and D-dimer level $\geq 1.5 \mathrm{ig} / \mathrm{ml}$ (Group II) respectively, The mean MRS was significantly $(p<0.05)$ higher in patients with D-dimer level $\geq 1.5 \mathrm{ig} / \mathrm{ml}$. On the other hand MRS belonged to $4-6$ in $20.4 \%$ in group I and $97.1 \%$ in group II.

The area under the Receiver-operating characteristic (ROC) curve for prediction of prognosis is depicted in table XV. Based on the Receiver-operating characteristic (ROC) curve $D$ dimer level had area under curve 0.972 . Receiveroperating characteristic (ROC) was constructed by using D-dimer level, which gave a cut off value 1.7, with $90.9 \%$ sensitivity and $89.4 \%$ specificity for prediction of prognosis. 
Table-I

Distribution of the study patients by age, survival and mortality $(n=88)$

\begin{tabular}{lcccccc}
\hline Age & \multicolumn{2}{c}{ Alive $(\mathrm{n}=66)$} & & \multicolumn{2}{c}{ Death $(\mathrm{n}=22)$} & P value \\
\cline { 2 - 3 } & $\mathrm{n}$ & $\%$ & & $\mathrm{n}$ & $\%$ & \\
\hline $40-49$ & 13 & 19.7 & & 2 & 9.1 & \\
$50-59$ & 19 & 28.7 & & 0 & 0 & \\
$60-69$ & 13 & 19.7 & & 12 & 54.5 & \\
$70-79$ & 14 & 21.3 & & 8 & 36.4 & \\
$\geq 80$ & 7 & 10.6 & & 0 & 0 & \\
Mean \pm SD & $59.97 \pm 12.41$ & & \multicolumn{2}{c}{$64.27 \pm 6.68$} & $0.125^{\text {ns }}$ \\
Range (min-max) & \multicolumn{3}{c}{$40-85$} & & \multicolumn{3}{c}{$47-70$} & \\
\hline
\end{tabular}

ns= not significant

$\mathrm{P}$-value was reached from unpaired t-test.

Table-II

Distribution of the study patients by risk factor, survival and mortality $(n=88)$

\begin{tabular}{|c|c|c|c|c|c|}
\hline \multirow[t]{2}{*}{ Risk factor } & \multicolumn{2}{|c|}{ Alive $(n=66)$} & \multicolumn{2}{|c|}{ Death $(n=22)$} & \multirow[t]{2}{*}{$P$ value } \\
\hline & $\mathrm{N}$ & $\%$ & $n$ & $\%$ & \\
\hline Hypertension & 55 & 83.3 & 15 & 68.2 & $0.128^{\mathrm{ns}}$ \\
\hline DM & 33 & 50.0 & 13 & 59.1 & $0.459^{n s}$ \\
\hline Hyperlipidemia & 21 & 31.8 & 11 & 50.0 & $0.124^{\mathrm{ns}}$ \\
\hline Smoking & 20 & 30.3 & 11 & 50.0 & $0.093^{\text {ns }}$ \\
\hline Others & 3 & 4.5 & 0 & 0.0 & $0.308^{n s}$ \\
\hline
\end{tabular}

ns= not significant

$\mathrm{P}$-value was reached from chi-squire test.

Table-III

Distribution of the study patients by MRS score with D-dimer level ( $n=88)$

\begin{tabular}{lccc}
\hline MRS score & & \multicolumn{2}{c}{ D-dimer level } \\
\cline { 2 - 4 } & $\mathrm{n}$ & Mean \pm SD & Min-Max \\
\hline 0 & 2 & $0.49 \pm 0.00$ & $0.49-.49$ \\
1 & 13 & $0.57 \pm 0.19$ & $0.49-1.00$ \\
2 & 6 & $0.49 \pm 0.00$ & $0.49-.49$ \\
3 & 23 & $0.70 \pm 0.33$ & $0.35-1.50$ \\
4 & 16 & $1.46 \pm 0.77$ & $0.49-2.90$ \\
5 & 6 & $1.60 \pm 0.59$ & $1.00-2.30$ \\
6 & 22 & $3.17 \pm 0.93$ & $1.50-4.50$ \\
\hline Pvalue & & $0.001^{\mathrm{s}}$ \\
\hline
\end{tabular}

$s=$ significant, $p$ value was reached from ANOVA test 
Table-IV

Distribution of the study patients byMRS and plasma D-dimer level ( $n=88)$

\begin{tabular}{|c|c|c|c|c|c|}
\hline \multirow[t]{3}{*}{ MRS } & \multicolumn{4}{|c|}{ D-dimer level } & \multirow[t]{3}{*}{$P$ value } \\
\hline & \multicolumn{2}{|c|}{$\begin{array}{c}\text { Group-I }(<1.5 \mu \mathrm{g} / \mathrm{ml}) \\
(\mathrm{n}=54)\end{array}$} & \multicolumn{2}{|c|}{$\begin{array}{c}\text { Group-II }(1.5 \mu \mathrm{g} / \mathrm{ml}) \\
(\mathrm{n}=34)\end{array}$} & \\
\hline & $\bar{n}$ & $\%$ & $\bar{n}$ & $\%$ & \\
\hline$\overline{0-3}$ & 43 & 79.6 & 1 & 2.9 & \\
\hline $4-6$ & 11 & 20.4 & 33 & 97.1 & \\
\hline Mean \pm SD & \multicolumn{2}{|c|}{$2.54 \pm 1.24$} & \multicolumn{2}{|c|}{$5.38 \pm 0.92$} & $0.001^{\mathrm{s}}$ \\
\hline Range(min-max) & \multicolumn{2}{|c|}{$0-5$} & \multicolumn{2}{|c|}{ 3-6 } & \\
\hline
\end{tabular}

$\mathrm{s}=$ significant

$\mathrm{p}$-value was reached from unpaired t-test.

Table-V

Receiver-operating characteristic (ROC) curve of D-dimer level prediction of prognosis.

\begin{tabular}{lcccccc}
\hline & $\begin{array}{c}\text { Cut off } \\
\text { value }\end{array}$ & Sensitivity & Specificity & $\begin{array}{c}\text { Area } \\
\text { under the } \\
\text { ROC curve }\end{array}$ & & \multicolumn{2}{c}{$\begin{array}{c}\text { 95\% Confidence } \\
\text { interval }(\mathrm{Cl})\end{array}$} \\
\cline { 3 - 7 } & & & & $\begin{array}{c}\text { Lower } \\
\text { bound }\end{array}$ & $\begin{array}{c}\text { Upper } \\
\text { bound }\end{array}$ \\
\hline D-dimer level & 1.7 & 90.9 & 89.4 & 0.972 & 0.944 & 1.000 \\
\hline
\end{tabular}

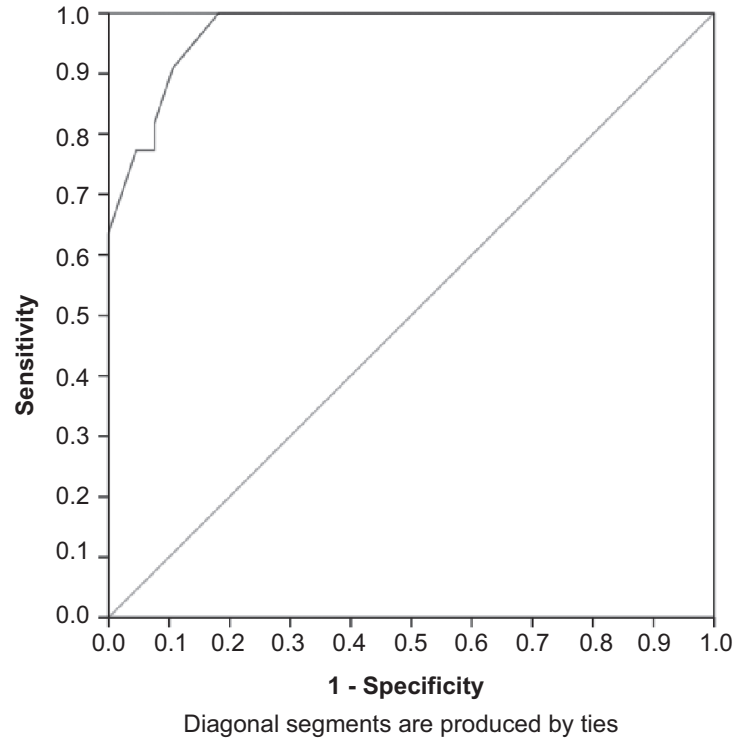

Fig.-1: Receiver-operating characteristic (ROC) curve of $D$-dimer level prediction of prognosis.

\section{Discussion:}

This observational study was carried out with an aim to assess the clinical presentation of the patients admitted with acute ischemic stroke and to observe the plasma D-dimer level on admission. This study also aimed to find out the short-term outcome of the patients according to Modified Rankin Scale (MRS) and to evaluate the relationship between plasma D-dimer level on admission and outcome of the patients at day $90 . \mathrm{In}$ this present study, it was observed that $28.4 \%$ patients belonged to age $60-69$ years. The mean age was $61.05 \pm 11.38$ years with ranged from 40 to 85 years. Yuan and Shi, (2014) find that themean age is $64.30 \pm 11.71$ years varied from 40 to 85 years which is consistent with the current study ${ }^{14}$.In this current study, it was observed that $64.8 \%$ patients were male and $35.2 \%$ were female and male to female ratio was almost 2:1. Similarly, Yuan and Shifind acute ischemic stroke patients 64.70 $\%$ males and $35.30 \%$ females, which is closely resembled with the present study ${ }^{14}$. In this current study, it was observed that the mean NIHSS score was $11.8 \pm 5.49$ with range from 1 to 23 . Yang et al. ${ }^{15}$ find the median NIHSS score on admission is 8 with in-terquartile ranges $5-11$ points. Similar findings was also observed by Zhang et al. ${ }^{16}$ 
D-dimer-a marker of fibrin turnover-exhibits unique properties as a biological marker of hemostatic abnormalities and thrombosis ${ }^{17}$. Elevated D-dimer level is reportedly a determinant of the incidence of ischemic stroke not only in the general population but also in patients with atrial fibrillation $(\mathrm{AF})^{18}$. In this present study, it was observed that the mean D-dimer level was $1.48 \pm 1.21$ (ìg/ml) with range from 0.35 to 4.5 (ig/ $\mathrm{ml}$ ). Yang et al. study assesses plasma D-dimer levels with regard to their accuracy to predict shortterm functional outcome in patients with AIS within 90 days in Chinese population and find the mean D-dimer level $1.36 \mathrm{ig} / \mathrm{ml}$ varied from $0.55-3.11 \mathrm{ig} /$ $\mathrm{ml}$, which is comparable with the current study ${ }^{19} . \mathrm{In}$ this present study, It was observed that $26.1 \%$ patients belonged to MRS score 3 . The mean MRS score was $3.64 \pm 1.79$ with range from 0 to 6 . Zhang et al. study observes an unfavorable functional outcome in $40.4 \%$ patients with a median MRS score of 4 having inter quartile range (IQR) 3 $6^{16}$. In another study Barber et al. (2004) also find an unfavorable functional outcome in $31.4 \%$ with a median MRS score of 4 having inter quartile range IQR, 3-6 ${ }^{20}$. In this current study, It was observed that $83.3 \%$ patients had hypertension in alive and $68.2 \%$ death, followed by $50.0 \%$ DM in alive and $59.1 \%$ in death, $31.8 \%$ Hyperlipidemia in alive and $50.0 \%$ in death, $30.3 \%$ Smoker in alive and $50.0 \%$ in death and $4.5 \%$ others in alive. The risk factorswas not statistically significant $(p>0.05)$ between two groups. Similarly, Yang et al. studyobserves that $62.9 \%$ patients had hypertension in good outcomes and $87.0 \%$ poor outcomes, followed by $19.9 \%$ DM in good outcomes and $44.9 \%$ in poor outcomes and $21.2 \%$ Smoker in good outcomes and $20.3 \%$ in poor outcomes. The difference of age is statistically not significant $(p<0.05)$ between two groups. Hypertension and DM are significantly higher in poor outcomes. Similar observations regarding the risk factors and prognosis are also observed by Zhang et al.According to association between MRS score with D-dimer level it was observed that the mean D-dimer level was $0.49 \pm 0.00$ found in MRS $0,0.57 \pm 0.19$ in MRS $1,0.49 \pm 0.00$ in MRS 2, $0.70 \pm 0.33$ in MRS $3,1.46 \pm 0.77$ in MRS 4 ,
$1.60 \pm 0.59$ in MRS 5 and 3.17 \pm 0.93 in MRS 6. This finding indicates that MRS score increased with mean D-dimer level significantly.

Patients those with MRS of $<3$ are predicted to have an independent life after stroke obtained by Sung et al. ${ }^{21}$. The investigators define MRS $\geq 3$ as moderate to severe acute ischemic stroke. In this present study, all patients were divided into two groups. Patients having D-dimer level $<1.5 \mathrm{ig} / \mathrm{ml}$ was considered as group I and D-dimer level $\geq 1.5$ $\mathrm{ig} / \mathrm{ml}$ was considered as group II. Regarding the association between MRS with D-dimer level the mean MRS was $2.54 \pm 1.24$ and $5.38 \pm 0.92$ in Group I and Group II respectively, The mean MRS was significantly $(p<0.05)$ higher in patients with $D$-dimer level $\geq 1.5 \mathrm{ig} / \mathrm{ml}$ (Group II). On the other hand MRS belonged to $4-6$ in $20.4 \%$ in Group I and $97.1 \%$ in Group II. Yang et al. obtain in their study that functional outcome is assessed by the modified Rankin Scale (MRS), a favourable functional outcome is defined as a MRS of $0-2$ points, whereas an unfavourable outcome is defined as a MRS of 3-6 points ${ }^{19}$.

In this present study it was observed that in the Receiver-operator characteristic (ROC) curves Ddimer level had area under curve 0.972 , which gave a cut off value 1.7 , having $90.9 \%$ sensitivity and $89.4 \%$ specificity for prediction of prognosis in patients with acute ischemic stroke. Yang et al. study report that higher D-dimer level is associated with an unfavorable functional outcome compared with those in patients with a favorable outcome. After adjusting for all other significant outcome predictors, D-dimer predicts poor outcome. The optimal cut-off value of plasma D-dimer levels as an indicator for diagnosis of unfavorable functional outcome is projected to be $1.99 \mathrm{mg} / \mathrm{L}$, which yields a sensitivity of $81.2 \%$ and a specificity of $79.7 \%$, the area under the curve is 0.84 with $95 \% \mathrm{Cl}, 0.79$ 0.90 , which are comparable with the current study. The investigators also mention that $\mathrm{D}$-dimer levels increase per unit patients having poor outcome increased more than 4 times greater as compared with patients who survived. After adjustment for possible parameters, D-dimer level remains as an independent predictor for mortality with an OR of 3.22 having $95 \% \mathrm{Cl}, 2.05-6.43$. Hamataniet al 
mention in their study that neither in-hospital nor 30-day ischemic stroke events are observed in patients with $\mathrm{D}$-dimer level less than the reference limit of normal $(<1.0 \mathrm{ig} / \mathrm{mL})^{22}$. This cutoff value of $1.0 \mathrm{ig} / \mathrm{mL}$ has a sensitivity of $100 \%$, achieving a negative predictive value of $100 \%$. Subgroup analyses show that D-dimer level is significantly associated with short-term ischemic stroke events in patients without atrial fibrillation $\mathrm{OR}=2.46 ; 95 \%$ $\mathrm{Cl}, 1.39-4.54$ for in-hospital ischemic stroke; and $\mathrm{OR}=2.20 ; 95 \% \mathrm{Cl}, 1.16-4.15$ for 30-day ischemic stroke and those without antithrombotic therapy OR=2.79; 95\% Cl, 1.53-5.57 for in-hospital ischemic stroke; and OR, 2.45; $95 \% \mathrm{Cl}, 1.30$ 4.91for 30-day ischemic stroke. Saver and Altman et al. find the correlation coefficients between NIHSS and the MRS at admission is $r=0.51^{23}$. Correlation analysis Sung et al. show a very significantly high correlation $(r=0.775)$ between NIHSS with MRS, index for severity of acute ischemic stroke and subsequent neurological impairment, respectively.

\section{Conclusion:}

This study has undertaken to determine the association between admission plasma D-dimer level and short-term outcome in patients with acute ischemic stroke. Acute ischemic stroke is more common in 60-69 years and above and male predominant. Hypertension, DM and hyperlipidemia are more common risk factor in Acute ischemic stroke and anterior circulation stroke is more common in this study. Age, sex, risk factors are not significantly associated with shortterm outcome in patients with acute ischemic stroke. NIHSS score and D-dimer level are significantly elevated in patients with acute ischemic stroke patients having poor outcome. MRS score and D-dimer level are significantly associated. The mean MRS is significantly higher in patients with D-dimer level e $1.55 \varnothing \mathrm{ípg} / \mathrm{ml}$. Ddimer level is a sensitive and specific predictive marker for short-term outcome in acute ischemic stroke. Therefore elevated plasma D-dimer level on admission is significantly associated with the poor prognosis in patients with acute ischemic stroke. There is a significant correlation found between NIHSS with MRS.

\section{References:}

1. WHO Fact sheet - The top ten causes of death (2015).

2. Indian economy overview, 2007

3. WHO Fact sheet (2011)

4. Meng, R, Wang, $X$, Hussain, M, Dornbos III, D, Meng, L, Liu, Y, Wu, Y, Ning, M, Ferdinando S, B, Lo, E.H. and Ding, Y. Evaluation of plasma D-dimer plus fibrinogen in predicting acute CVST. International Journal of Stroke, 2014; 9(2), pp.166-73.

5. Haapaniemi, E and Tatlisumak, T. Is D dimer helpful in evaluating stroke patients? A systematic review. Acta Neurologica Scandinavica, 2009; 119(3), pp.141-50.

6. Lowe, G.D and Rumley, A. Use of fibrinogen and fibrin D-dimer in prediction of arterial thrombotic events. Thrombosis and haemostasis, 1999;82(08), pp.667-72.

7. Mahe, I, Bergmann, J.F, Chassany, O, Simoneau, G, Drouet, L and COAGFA Group, A multicentric prospective study in usual care: D-dimer and cardiovascular events in patients with atrial fibrillation. Thrombosis research,2012; 129(6), pp.693-99.

8. Goldenberg, N.A, Jenkins, S, Jack, J, Armstrong-Wells, J, Fenton, L.Z, Stence, N.V, Oleszek, J, Boada, R, Wilkening, G.N, Wilkinson, C and Soep, J.B. Arteriopathy, Ddimer, and risk of poor neurologic outcome in childhood-onset arterial ischemic stroke. The Journal of pediatrics, 2013; 162(5), pp.1041-46

9. Yuan, W and Shi, Z.H. The relationship between plasma D-dimer levels and outcome of Chinese acute ischemic stroke patients in different stroke subtypes. Journal of Neural Transmission,2014; 121(4), pp.409-13.

10. Koch, H.J, Horn, M, Bogdahn, U and Ickenstein, G.W. The relationship between plasma D-dimer concentrations and acute ischemic stroke subtypes. Journal of Stroke and Cerebrovascular Diseases,2005; 14(2), pp.75-9. 
11. Park, Y.W, Koh, E.J and Choi, H.Y. Correlation between serum $\mathrm{D}$-dimer level and volume in acute ischemic stroke. Journal of Korean Neurosurgical Society,2011; 50(2), p.89.

12. Berge, E, Friis, $P$ and Sandset, P.M. Hemostatic activation in acute ischemic stroke. Thrombosis research,2001; 101(2), pp.13-21.

13. Haapaniemi, $E$ and Tatlisumak, T. Is D dimer helpful in evaluating stroke patients? A systematic review. ActaNeurologica Scandinavica,2009; 119(3), pp.141-50.

14. Yuan, Wand Shi, Z.H. The relationship between plasma $\mathrm{D}$-dimer levels and outcome of Chinese acute ischemic stroke patients in different stroke subtypes. Journal of Neural Transmission, 2014; 121(4), pp.409-13.

15. Yang, X.Y, Gao, S, Ding, J, Chen, Y, Zhou, X.S. and Wang, J.E. Plasma D-dimer predicts short-term poor outcome after acute ischemic stroke. PLoS One,2014; 9(2), p.e89756.

16. Zhang, J.L, Yin, C.H, Zhang, Y, Zhao, L.B, Fu, H.J and Feng, J.C. Plasma copeptin and long term outcomes in acute ischemic stroke. ActaNeurologica Scandinavica, 2013; 128(6), pp.372-80.

17. Weitz, J.I, Fredenburgh, J.C. and Eikelboom, J.W. A test in context: D-dimer. Journal of the American College of Cardiology,2017; 70(19), pp.2411-20.

18. Sadanaga, T, Sadanaga, M. and Ogawa, S. Evidence that D-dimer levels predict subsequent thromboembolic and cardiovascular events in patients with atrial fibrillation during oral anticoagulant therapy. Journal of the American College of Cardiology, 2010; 55(20), pp.2225-31.

19. Yang, X.Y, Gao, S, Ding, J, Chen, Y, Zhou, $X$..and Wang, J.E. Plasma D-dimer predicts short-term poor outcome after acute ischemic stroke. PLoS One,2014; 9(2), p.e89756.

20. Barber, M, Langhorne, P, Rumley, A, Lowe, G.D and Stott, D.J. Hemostatic function and progressing ischemic stroke: D-dimer predicts early clinical progression. Stroke,2004; 35(6), pp.1421-25.

21. Sung, P.H, Chen, K.H, Lin, H.S, Chu, C.H, Chiang, J.Y and Yip, H.K. The Correlation between Severity of Neurological Impairment and Left Ventricular Function in Patients after Acute Ischemic Stroke. Journal of clinical medicine, 2019; 8(2), p.190.

22. Hamatani, $Y$, Nagai, $T$, Nakai, M, Nishimura, $\mathrm{K}$, Honda, Y, Nakano, H, Honda, S, Iwakami, $\mathrm{N}$, Sugano, Y,Asaumi, Y and Aiba, T. Elevated Plasma D-Dimer Level Is Associated With Short-Term Risk of Ischemic Stroke in Patients With Acute Heart Failure. Stroke, 2018; 49(7), pp.1737-40.

23. Saver, J.. and Altman, H. Relationship between neurologic deficit severity and final functional outcome shifts and strengthens during first hours after onset. Stroke,2012; 43(6), pp.1537-41. 